\title{
CRAFT AS A BOUNDARY TOOL FOR MULTI-AND INTERCULTURAL EDUCATION: A CASE IN TEACHER EDUCATION
}

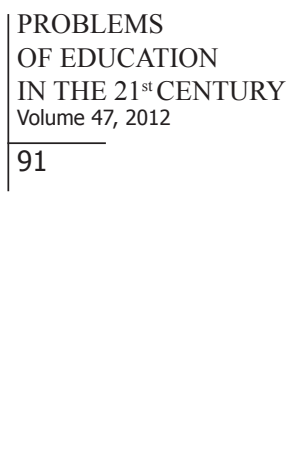

\author{
Tarja Kröger \\ University of Eastern Finland, Savonlinna, Finland \\ E-mail: tarja.kroger@uef.fi
}

\begin{abstract}
Studies on boundary crossing and boundary objects emphasize that boundaries carry potential for learning. However, it is not explicated how the craft could be used as a boundary in multi-and intercultural education. This research describes a case of using craft as a boundary to facilitate multi-and intercultural education. It first gives an overview on the Multi- and Intercultural Craft course including a theoretical part that was organized through a virtual platform, Moodle. The course included also a practical part, a project, where Finnish, exchange students and a group of immigrants from Burma met in the context of craft. The students $(n=14)$ were asked to write reflective essays about the course. In the qualitative analysis of essays, their learning experiences that appeared in the data, were examined. Three aspects of learning experiences were identified: first a cognitive aspect, which is about increased knowledge; second an affective aspect, which focuses on changing attitudes; and the third an interactive aspect, which is concerned with how to get on with people from different cultures.

Key words: boundary object, craft education, intercultural education, multicultural education, teacher education.
\end{abstract}

\section{Introduction}

Finland is experiencing increased cultural diversity due to immigration and is facing challenges in developing multi- and intercultural education in schools and in teacher education.

Studies on boundary crossing and boundary objects emphasize that boundaries are relevant for learning (see e.g. Wenger, 1998). The claims on boundaries and learning made in the literature are often general in nature, and the literature hardly explicates how or what kind of learning is taking place (Akkerman \& Bakker, 2011, p. 133).

\section{Multi- and Intercultural Education}

Terms multicultural and intercultural are used interchangeably, sometimes they are differentiated. Critically oriented researchers argue that there are no major differences between critical multicultural education and critical intercultural education (Mansikka \& Holm, 2011).

UNESCO (2006) differentiates multi- and intercultural education in the following way: "Multicultural education uses learning about other cultures in order to produce acceptance, or at least tolerance, of these cultures. Intercultural education aims to go beyond passive coexistence, to achieve a developing and sustainable way of living together in multicultural societies through 
PROBLEMS

OF EDUCATION

IN THE $21^{\text {st }}$ CENTURY

Volume 47, 2012

2 the creation of understanding of, respect for and dialogue between the different cultural groups." Interculturality implies, by definition, interaction, learning with others rather than learning about other cultures from a distance.

In this research, the concept of intercultural education is interpreted in the way UNESCO defines it, but it is also understood that they can be used as companions to help educators to work with their diverse learners.

\section{Boundary Objects}

The concept of boundary objects comes from Star and Griesemer (1989) who introduced the concept of boundary object to indicate how artifacts can fulfill a specific function in bridging intersecting practices. Situated action theorists (e.g. Lave and Wenger, 1991) have demonstrated that it is the situation that drives people's learning and behaviour, rather than goals. Boundary objects are tools to facilitate interactions in these situations. A boundary object could be artifacts, documents, terms, concepts and other forms of reification that can help people from different communities build a shared understanding (Wenger, 1998). In this paper, a boundary object refers to a craft as an artifact and as a process.

There are different ways in which scholars have approached learning on the boundary. Akkerman and Bakker (2011) have analyzed the learning processes described in the studies on boundary crossing and boundary objects. The review of the studies reveals four potential learning mechanisms that can take place at boundaries: identification, coordination, reflection, and transformation. Identification is about coming to know what the diverse practices are about in relation to one another. Coordination is about creating cooperative and routinezed exchanges between practices. Reflection is about expanding one's perspectives on the practices. Transformation is about collaboration and codevelopment of practices. (Akkerman and Baker, 2011.)

\section{Problem of Research}

Prospective teachers need to be encouraged to develop multi- and intercultural education. The following case shows how craft can be used as a boundary in multi- and intercultural education. The research question is: what kind of learning experiences students get during the course where craft is used as a boundary tool for multi- and intercultural education.

\section{Methodology of Research}

The qualitative case study design was chosen because it is useful to understand learning experiences in multi- and intercultural education and to improve education academically. Case studies include an intensive process of collecting the research data (Merriam, 1998). In this case study, the research data were collected through reflective essays. The essays were analyzed qualitatively.

Fourteen prospective teachers participated in this study. Of which, ten participants were Finnish students and four were exchange students. Reflective essays were written by all students (14). The essay task was rather open, the page limit was about 5-10 pages. First, they were asked to write about meeting people from other cultures and developing cultural sensitivity in the context of crafts during and after the course. Second, they were asked to reflect on both difficulties and pleasurable learning experiences. They were also asked to reflect on the lectures/readings and assignments of the course.

The texts were repeatedly read in order to determine the distinct ways in which the students described their learning. In addition to differences in forms of expression, attention was 
also paid to similarities. The categories resulting from the analysis cover the whole variation of different ways in which the students described their subjective learning outcomes.

The researcher's role in this qualitative case study is an insider-researcher. Insiderresearchers are those who choose to study a group to which they belong. He interacts and collaborates with the participants, and he gathers data by himself (Unluer, 2012). There are both advantages and disadvantages to being an insider-researcher. As an insider it is easy to determine the case, to enter the research site, to define the researcher's role to participants and to access data. On the other hand, an insider researcher may encounter some problematic situations in considering the ethical issues. The instructor/researcher had to be careful not to give the impression that students were tested when they wrote their reflective essays. The lecturer/researcher emphasized to the students that the question was not to test but to understand the participants' learning experiences about the subject.

\section{The Case}

The course was held at the University of Eastern Finland's Department of Applied Education Science and Teacher Education in spring 2011 during two months. The course was aimed at crafts science students who will become teachers. The course followed a blended learning methodology, which combines attended learning and on-line learning. On-line activities took place in a learning environment Moodle and hand-on activities took place in classrooms. Ten Finnish students and four exchange students (two from Latvia and two from Spain) registered for this course.

The course had three primary goals. The first goal was to introduce the participants to multi- and intercultural concepts and cultural sensitivity. Secondly, the course was designed to provide motivation, knowledge, and an appreciation of diversity that can help to overcome many obstacles to intercultural understanding and communication. Thirdly, the goal was to help improve intercultural communication in the context of craft culture. That is, what antecedents and considerations need to be taken into account when people from different cultures come together to share ideas and information? Finally, the goal was to encourage future teachers to reflect on and identify their own personal positions, in various environments, in order to develop a clearer sense of their ethnic and cultural identities and to examine their cultural sensitivity vis-à-vis people from different cultures.

\section{Orientation to the Course}

The course started with a pre-task where students were asked to write a short essay about the theme"Me and multiculturalism". After completing the pre-task, students were asked to browse through the virtual Moodle environment and the document of the course syllabus and program. Students were also asked to make an introduction using the discussion forum of Moodle. A diverse student group with different backgrounds and experiences was in itself seen as an important resource in this course.

\section{Lectures/readings and Assignments}

The students were asked to listen to asynchronous lectures and perform asynchronous assignments in the virtual Moodle environment. Because the lectures were in Finnish, the exchange students were given some English readings instead of Finnish lectures. Lectures/ readings were given two times a week. In total, there were five topics for the lectures/readings. The lectures included a bibliography and recommended links.

In addition to lectures/readings, associated activities - assignments - were given in 
PROBLEMS

OF EDUCATION

IN THE $21^{\text {st }}$ CENTURY

Volume 47,2012

Moodle. The purpose of the assignments was to stress important points of lectures/readings, clarify theoretical concepts, stimulate ideas and foster study of craft culture. The course comprised two main types of assignments. The first type included independent activities. In the second type of assignments, students were asked to express considerations, doubts, queries and comments to each other's posts.

The lectures, readings and tasks were available from the given day and the students had a week to complete the task connected to a lecture or specific readings. After a week, the lecturer made a summary of the students' answers. Summing-ups were provided to the students through Moodle.

The following topics were discussed during five lectures/readings and tasks.

- Multi- and interculturalism: concepts and sensitivity

- Characteristics of Finnish craft culture and other cultures

- Cultural signs and meanings of minority cultures and subcultures

- Representations of cultures

- Practices of multi- and intercultural pedagogy

\section{Project}

Reflection on a cognitive level is not enough; the emotional level, too, should be taken into account (Alasuutari \& Jokikokko, 2010, p. 30). A vital question is, what kinds of experiences make students not only aware of intercultural issues, but also help them translate their knowledge into action. Some researches (Mezirow, 1991; Jokikokko, 2009) have shown that emotionally powerful experiences play a significant role in the transformation process. In this course, project work was used for this purpose. The project used the principle of learning of the real case that stimulates learning and converts it in to a significant process.

In the project, students were supposed to meet refugees from Burma and organize a craft workshop for people who are just beginning to learn Finnish and don't know much about the Finnish culture. The instructor explained the idea of the project in the first face-to-face session and gave a task to plan content for the first meeting (two hours) and the workshop (four hours) with the refugees and the exchange students. The main information was also published in the virtual environment. The students were given the following support questions for planning the first meeting:

- What and how do you tell about yourself?

- What and how do you tell about your craft culture?

- What do you want to know about the guests?

- How do you show your interest in the strangers?

The Finnish students worked in pairs so that every pair would later include five refugees and one exchange student to their group. The students made their plans first in pairs and later presented them to the whole group in the second face-to-face session. Students had the opportunity to use the virtual wiki forum in Moodle for planning.

The plans for the meeting and the workshop with the refugees were presented and discussed in the second face-to-face session. The face-to-face session aimed to training students for collaboration and boundary crossings in the context of craft. It aimed also to creating a safe, trusting and open atmosphere within the group.

When the Finnish students, the exchange students and the refugees met for the first time in the meeting, they brought (craft) artefacts with them to show to each other. The artefacts that they brought with them were recognizable and common enough for them to talk about. The craft artefacts worked as a common point of reference for the conversations. The students and the refugees realized that some of the techniques like weaving and materials like wool were familiar for them regardless of their diverse backgrounds. Although crafts were made with 
common techniques and structures, people attached different meanings on them. For example, weaving has been an essential way of getting money for living for the Burmese people. To the Finnish students weaving often represented so called 'slow craft' carrying a therapeutic meaning. Despite the different interpretations, boundary craft objects served as a means of understanding each other.

The dialogue continued after a week in the craft workshops which were organized by the Finnish students. The small groups were the same in the workshops as in the first meetings, i.e. two Finnish students, five refugees and one exchange student in a group. All groups had a common theme "Let's take part in the world's biggest blanket -project". "The world's biggest blanket" project was a national craft project that anyone could take part in. Small blankets (parts of the world's biggest blanket) were donated to charities after "The world's biggest blanket" event. The participants crocheted together patches for the blanket in the workshops. While learning and making they shared experiences, recognised similarities and differences, and came to understand each other.

After the workshop, volunteering students gathered together and stitched the patches together. The blanket was named "Diversity is richness". The completed blanket was put on display and also photos were taken of it and sent to the participants of the workshop. The students attached some manifestos to the blanket that was on display. The blanket is also displayed on the web page http://www.kaspaikka.fi/koti/savonlinna/monikulttuurisuuspeitto/index.html.

\section{Results of Research}

In the analysis of essays, students' learning experiences that appeared in the data, were examined. Three different aspects emerged from the essays: cognitive aspect (knowing), affective aspect (understanding and valuing) and interactive aspect (behavior and communication).

In the following there is an overview of the students' perceptions of the various learning experiences. Direct quotations from students are in italics.

The cognitive aspect refers to knowing about others, their behaviour, culture, history, country. There were descriptions of learning experiences where students say that they value the information they learned from the Burmese culture.

The most rewarding thing was to see that the Burmese people have a lot of craft knowhow, and we can learn from them.

This course deepened my previous knowledge about the Burmese culture.

The cognitive aspect also includes knowledge about the similarities and differences between cultures.

It is always interesting for me to learn things about other cultures, but this experience was so much better, because this time I had a chance to meet people from other culture and it helped me to look deeper in cultures than just on the cover, like through pictures. I saw how they move, act, look, speak and work. It made me more sensitive in understanding that the things that are so common for me are something very unusual to others.

Affective aspect refers to accepting, respecting and appreciating others. Students described how their attitudes have changed and cultural sensitivity has increased during the course by looking from another perspective. Taking another perspective is a way to begin to see things in a different light. 
PROBLEMS

OF EDUCATION

IN THE $21^{\text {st }}$ CENTURY

Volume 47,2012

I started to think about what I would miss from my home if I had to go to another country as an immigrant. I realized that it is certainly not easy for the Burmese people to take up the Finnish language and culture.

Learning experiences on the affective level were often connected to significant persons met during the project. Jokikokko (2009) has analyzed biographical interviews in which Finnish teachers were asked to talk about their lives from the perspective of intercultural learning. The analysis of the interviews showed that other people were involved in many of the experiences being referred to, and that these individuals played an important role in the stories. In the essays of this course, there were also comments about significant persons. A significant individual is described as an emphatic person or an equal interlocutor.

It was an awesome experience when an old Burmese woman taught me her own crochet model. It was a good experience for me because I understood what it is like to learn something new without the same language. On the other hand the experience of teaching and that someone really appreciates and wants to learn from your traditions, was a rewarding experience for the Burmese woman and the whole group.

I met a very warm, emphatic Afghan woman in our workshop. She was so positive and gentle, a good role model for every one of us.

Learning experiences of the interactive aspect were connected to the social events, behaviour, in the workshop and experiences of craft as a tool for communication. The descriptions of behaviour included experiences of a positive atmosphere in the group. The positive atmosphere was described as familiar, supportive and warm.

It was great to see that the second meeting with refugees was more informal and we clearly managed to gain trust of the foreigners. We even managed to found a common humour, although a common language was weak.

The best thing definitely was working together in a workshop with the refugees and the exchange students. Co-operation was smooth and everybody was eager.

Learning experiences included many descriptions of craft as a tool for communication. The possibility to communicate without a common language was emphasized in the descriptions.

Craft is a different way to interrelate and enriching oneself, while very useful for establishing a communication with those who do not speak the same language. It also provides a cultural exchange between different cultures involved in this process, making the experience much more usable: teaching and learning from craft.

The crafts have been the perfect excuse to meet and at the same time to explore the enriching characteristics of the people and the Burmese/Finnish culture. Finding different ways to communicate has been a challenge. We have seen that there are many ways to say something. Words are not everything. Crafts can be a way to express yourself and understand the others.

The project has helped me to get a new perspective on working with people from other cultures. Often people think that making a multiculturalism project is not possible because, if the two groups do not speak the same language, the communication is not possible and then the project serves no purpose. But now I've seen that we do not need fluent verbal communication to interact with a cultural group different from yours. 
The meaning of craft got a new perspective. Although we had not a common language, craft making connected us.
\end{abstract}

When we meet people from different cultures and we share a common interest, we can understand each other even though we do not have a common language. The greatest experience during this course was to meet without a common language.

\title{
Discussion
}

The results give us clues that craft as a boundary object has at least three aspects: cognitive, affective and interactive. These aspects can be equated approximately to the domains of intercultural competence (see e.g. Chen and Starosta, 1998; Lustig and Koester, 2006; Bennett, 2008).

Cognitive aspect is about getting knowledge about one's own as well as other cultures. It also includes knowledge about the similarities and differences between cultures. Craft as a boundary can be seen as a knowledge-transforming device. Hill (2006) reminds that it is important to go deeper than the superficial, easily recognizable characteristics of a particular culture. Students should be encouraged to compare variability across a number of cultures, for example, between individualism and collectivism: the extent to which a society is structured around a group mentality or each person acting individually. Students' descriptions of cultural knowledge in this research are on a very general level. Therefore, future research should take this issue into account; one possible suggestion is to use an interview as a research method.

Hill (2006) points out that cultural knowledge is an important component, but it is not enough for intercultural understanding. Positive attitudes, such as empathy, curiosity and respect, are also necessary for intercultural understanding. Knowledge about another culture can lead to an appreciation of that culture but the adoption of a positive attitude towards other does not stem from knowledge alone (Hill 2006.) Positive attitudes are described here as an affective aspect. A person's affective response to intercultural difference can be called also intercultural sensitivity (Straffon 2003). Affective aspect here is about accepting, respecting and appreciating others through craft objects and craft skills that are important for individuals. Craft as a boundary creates a possibility to look at oneself through the eyes of other worlds. Boland and Tenkasi (1995) call this perspective taking. They argue that boundary objects are artifacts that can serve as a perspective-taking experience for those who have the attitude of taking of the other into account (p. 362).

For Weber (2003; 2005), who has introduced an intercultural encountering model, intercultural learning and development is a collective activity where face-to-face encounters are important. The importance of face-to-face encounters can be seen also in this case. It seems that craft could provide a physical layout that allow participants to be and communicate together even without a common language. This is called here an interactive aspect. Interactive aspect is about experiences of ability to interact effectively and appropriately with people from other cultures. It includes experiences of positive atmosphere in a group and experiences of craft as a tool for communication.

There are also studies which report that artifacts can fail as boundary objects when they do not fully or rightfully capture multiple meanings and perspectives (Akkerman \& Baker, 2011, p. 141). To understand more precisely what the learning potential craft as a boundary tool entails, more research is needed.

This research is exploratory and the report is an initial analysis. Thus caution and prudence apply and it is necessary to contrast the findings with others cases. To move forward, both more empirical research and conceptual development are needed to interpret how craft works as a boundary tool across different contexts. It is also important to collect more data by conducting interviews about experiences of refugees. 


\section{PROBLEMS \\ OF EDUCATION \\ IN THE $21^{\text {st }}$ CENTURY \\ Volume 47, 2012 \\ 98 Conclusions}

The purpose of the present paper was to describe a case about using craft as boundary object for multi- and intercultural education and to examine learning experiences of the students. Talking about crafts and making crafts together is not really new. What is new is a need to become more intentional and systematic about fostering craft as a boundary object for multiand intercultural education.

Three aspects of learning experiences were identified when craft was used as a boundary object: a cognitive, an affective and an interactive aspect. There is one conclusion that holds for all three aspects: Boundary crossing does not mean moving from multiplicity to homogeneity but rather a process of establishing continuity in diversity. Students and refugees can all agree they are talking about craft but they are not actually talking about the same thing. They attach different meanings to craft, it is used differently, for different purposes. Despite different interpretations, craft is common enough to serve as a means of working together, communicating and understanding each other.

The case gives clues that craft could be used as a boundary object through which a teacher can provide opportunities for researching information, extending awareness and knowledge, deepening understanding, exploring values, and making comparisons and contrasts of differences and similarities between cultures in positive ways, without stereotyping or making judgments, and practicing craft together and seeing that craft connects people.

\section{References}

Akkerman, S. F., \& Bakker, A. (2011). Boundary Crossing and Boundary Objects. Review of Educational Research, 81 (2), 132-169.

Alasuutari, H., \& Jokikokko, K. (2010, June 1). Intercultural Learning as a Precondition for More Inclusive Society and Schools. Finnish Journal of Ethnicity and Migration, 5 (3), 27-37. Retrieved from http://www.etmu.fi/fjem/pdf/FJEM_3_2010.pdf

Bennett, J. M. (2008). On becoming a global soul: A path to engagement during study abroad. In V. Savicki (Ed.), Developing intercultural competence and transformation: Theory, research and application in international education. Sterling: Stylus, 13-31.

Boland, R. J., \& Tenkasi, R. V. (1995). Perspective making and perspective taking in communities of knowing. Organization Science, 6, 350-372.

Chen, G. M., \& Starosta, W. J. (1998). Foundations of intercultural communication. Boston, MA: Allyn \& Bacon.

Hill, I. (2006). Student types, school types and their combined influence on the development of intercultural understanding. Journal of Research in International Education, 5 (1), 5-33.

Jokikokko, K. (2009). The role of significant others in the intercultural learning of teachers. Journal of Research in International Education, 8 (2), 142-163.

Lave, J., \& Wenger, E. (1991). Situated learning: Legitimate peripheral participation. Cambridge, UK: Cambridge University Press.

Lustig, M. W., \& Koester, J. (2006). Intercultural competence: Interpersonal communication across cultures. $5^{\text {th }}$ Ed. Boston, MA: Pearson.

Mansikka, J., \& Holm, G. (2011). Teaching minority students within minority schools: Teachers' conceptions of multicultural education in Swedish-speaking schools in Finland. Intercultural Education, 22 (2), 133-144.

Merriam, S. B. (1998). Qualitative research and case study applications in education (2nd Ed.). San Francisco: Jossey-Bass.

Mezirow, J. (1991). Transformative Dimensions of Adult Learning. San Francisco: Jossey-Bass.

Star, S. L., \& Griesemer, J. R. (1989). Institutional Ecology, 'Translations' and Boundary Objects: Amateurs and Professionals in Berkeley's Museum of Vertebrate Zoology. Social Studies of Science, 19 (3), 387-420. 
Straffon, D. A. (2003). Assessing the intercultural sensitivity of high school students attending an international school. International Journal of Intercultural Relations, 17 (4), 487-501.

UNESCO (2006). Guidelines on Intercultural Education. Retrieved from http://unesdoc.unesco.org/ images/0014/001478/147878e.pdf

Unluer, S. (2012). Being an Insider Researcher While Conducting Case Study Research. The Qualitative Report 201, Volume 17, Article 58, 1-14. Retrieved August 1, 2012 from http://www.nova.edu/ ssss/QR/QR17/unluer.pdf

Weber, S. (2003). Boundary-crossing in the context of intercultural learning. In T. Tuomi-Gröhn \& Y. Engeström (Eds.) Between school and work: New perspectives on transfer and boundary-crossing (pp. 157-177). Oxford: Elsevier Science, EARLI.

Weber, S. (2005). Intercultural learning as identity negotiation. Frankfurt am Main: Peter Lang.

Wenger, E. (1998). Communities of Practice- Learning. Learning, Meaning, and Identity. New York: Cambridge University Press.

Advised by Vincentas Lamanauskas, University of Siauliai, Lithuania

Received: August 27, 2012

Accepted: October 13, 2012

Tarja Kröger

Ph.D, Senior Lecturer in Craft Science, University of Eastern Finland, Kuninkaankartanonkatu 5-7, P.O. Box 86, Fl-57101 Savonlinna, Finland.

E-mail: tarja.kroger@uef.fi

Website: http://www.uef.fi/uef/english $\mid$\begin{tabular}{l} 
PROBLEMS \\
OF EDUCATION \\
IN THE 21 $1^{\text {st }}$ CENTURY \\
Volume 47, 2012 \\
\hline 99
\end{tabular}

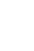

